\title{
EXPERIMENTAL AND THEORETICAL RESEARCH ON RCFT BEAM-COLUMNS FABRICATED WITH Q420B HIGH-STRENGTH STEEL SUBJECTED TO ECCENTRIC LOAD
}

\author{
Zhi-Hua Chen ${ }^{1,2}$, Rui Ma ${ }^{2}$, Yan-Sheng Du ${ }^{2,3, *}$ and Ming Lian ${ }^{4}$ \\ State Key Laboratory of Hydraulic Engineering Simulation and Safety, Tianjin, China \\ ${ }^{2}$ School of Civil Engineering, Tianjin University, Tianjin, China \\ ${ }^{3}$ State Key Laboratory of Green Building in Western China, Xi 'an University of Architecture \& Technology, Xi'an, China \\ ${ }^{4}$ School of Civil Engineering, Xi'an University of Architecture and Technology, Xi'an, China \\ * (Corresponding author: E-mail: duys@tju.edu.cn)
}

\section{A B S T RA C T}

This study is motivated by the widespread use of concrete - filled tubular (CFT) columns and the increasing use of high strength steel (HSS). However, due to limited research, HSS was not extensively utilized in rectangular concrete - filled tubular (RCFT) columns. In this paper, the behavior of RCFT columns manufactured with Q420B HSS subjected to eccentric load was studied through the method of experimental and finite element (FE) analysis. The eccentric compression test was conducted on seventeen specimens with different concrete strength, width - to - thickness ratio, aspect ratio, and excentricity ratio. It obtained and discussed failure modes, load-vertical displacement curves, load-lateral deflection curves, and variations in strain. ABAQUS software developed nonlinear FE models based on an experimental program. Several specifications, including EC4, AISC360, AIJ, GB 50936-2014, and DB 29-57 for predicting the ultimate capacities of RCFT columns under excentric loading, were discussed through comparison with experimental results. The proposed approaches were also verified to be reasonably conservative for practical design with the experimental results.
ART I CLE H IS TORY

$\begin{array}{ll}\text { Received: } & \text { 24 February } 2020 \\ \text { Revised: } & \text { 20 June } 2020 \\ \text { Accepted: } & \text { 22 June } 2020\end{array}$

\section{K E Y W O R D S}

Rectangular concrete-filled tubular columns;

Experiment investigation;

Finite element analysis;

Design approach;

High-strength steel

\section{Introduction}

Concrete - filled steel tubular (CFT) columns have been extensively used in various structural engineering fields, such as high - rise buildings, bridges, residential structures, and so on[1-3]. Compared to square and circular columns of CFT[4], rectangular sections comprising steel and concrete are non-niform and more complex. Meanwhile the rectangular concrete - filled steel tubular (RCFT) column, as a kind of thin - walled component, is susceptible to local steel tube buckling. Hence, in recent years, the RCFT columns have attracted considerable attention. Some researchers (Du et al.[5], Hernán-dez-Figueirido et al.[6], Lai et al.[7], Lee et al.[8], Long et al.[9], Ding et al.[10], Wang et al.[11], Young et al.[12], and Du et al.[13]) used experimental and theoretical methods to study mechanical behavior in relation to normal RCFT columns.

High - strength steel (HSS) manufacturing and welding techniques have been developed rapidly over the past few years, making it possible to use HSS extensively in engineering construction. Several researchers performed experimental and theoretical studies on this kind of material to determine the mechanical performance of HSS in structure projects. Shi et al.[14] systematically explored the mechanical performance of HSS and offered some suggestions for design. Wang et al.[15] proposed a yield function and basically simulated HSS elastoplasty behavior in complex stress conditions. Li et al.[16] offered experimental and theoretical support to design and exploit members of the HSS. The findings suggest that initial imperfection should be considered during analyzes of finite elements. In China, CFT members with a mild carbon steel are the main objects of current CFT structure design specifications. CFT-focused component requirements and structures using HSS were not published. It would appear that further investigations are needed to determine if existing CFT structure codes could be extended to the designing of RCFT members and structures using HSS.

Some experimental and theoretical studies have been reported in recent years on the bearing capacities of CFT columns made from HSS, while most of them were under axial load. For example, Lue et al.[17], Liew etal.[18], Xiong et al.[19], and Lyu et al.[20] performed extensive experimental axial programs to reveal the actions of CFT columns composed of high - strength steel $\left(f_{\mathrm{y}}=379.8 \mathrm{MPa} \sim 780 \mathrm{MPa}\right)$ and ultra - high - strength concrete $\left(f_{\mathrm{c}}^{\prime}=84 \mathrm{MPa} \sim 190 \mathrm{MPa}\right)$, to extend the database of tests. Steel grade has a significant effect on the axial capacities of the RCFT columns, according to Du et al.[21]. Lee et al.[22] concentrated on evaluating the effect of slenderness on the mechanical performance of high - strength steel CFT columns (grade 800MPa). Ellobody and Young[23] developed a nonlinear finite ele- -ment ( FE) model with considerable accuracy of CFT columns with a square and rectangular hollow section to further understand the behavior of CFT columns under axial load. They carried out a parametric analysis to determine the effect of concrete strengths and cross -section geometries.

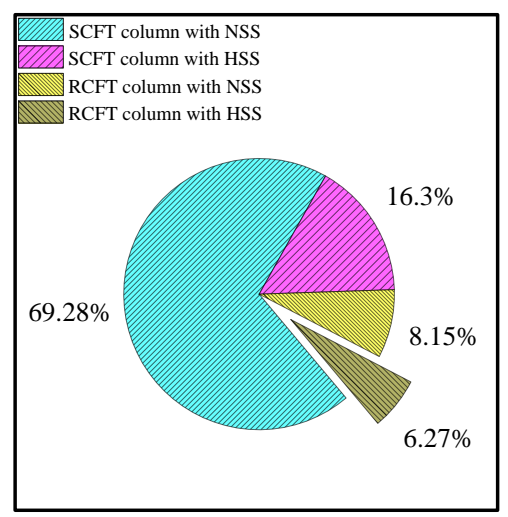

Fig. 1 Test database of square and RCFT beam-columns

To fully grasp the research status of CFT beam-columns under excentric loading, a database was developed and analyzed, as shown in Fig. 1, including 319 test results from previous literatures. Many test data came from square concrete-filled steel tubular (SCFT) columns made of normal strength steel (NSS), whereas just 6.27 percent were connected to RCFT columns with HSS, suggesting that there is still a shortage of experimental studies and theoretical study of the mechanical properties of excentric RCFT columns made of HSS. Reference [24] established the experimental system of sixteen stub columns and four slender CFT columns subjected to eccentric loading. The research findings showed the need for a revision of the application codes to design high - strength CFT columns. Choi et al.[25] studied the structural behavior of HSA800 high strength steel and SM490 mild steel hybrid RCFT columns subjected to weak axis bending, made of thick flanges and thin webs, respectively. The test results showed that using this type of section could dramatically reduce costs without degradation of the performance. Du et al.[26,27] investigated RCFT column output using Q460 grade steel under eccentric loads and suggested a new design approach. However, the approach considered backing plate resistance which is not common in RCFT columns. 
Li et al.[28] experimentally studied 434MPa HSS concrete -filled square tube stub columns with different excentricity ratios. The effects of eccentricity ratio, concrete compressive, strength, steel yield strength and steel ratio were analyzed in detail but no consideration was given to the longitudinal effect. According to $\mathrm{Li}$ et al.[29], two important factors affecting bearing capacities are the steel ratio and the slenderness ratio. Earlier overall work did not conduct systematic column research using Q420 grade steel produced in China.

This paper presents further study of RCFT columns manufactured with Q420B HSS by conducting new experiments, setting numerical models and proposing theoretical formulae. The goal is to explore these component's mechanical behaviors under combined axial compression and bending. Firstly, an experimental program of 17 specimens is reported with different parameters. There are presented the modes of failure, load versus vertical displacement / lateral deflection, and load versus strain behaviors. The effects of concrete in-fill, the ratio of width to thickness and the ratio of eccentricity are discussed. The FE models are established and verified by experimental data for further analysis of the behavior of RCFT columns under loading process. By comparison with the experimental findings, predictions calculated using current design codes of different countries are discussed. It is also compared and tested that the proposed design approach based on the Chinese design code is relatively conservative for practical design. This research work may support the widespread use of Q420B high - resistance steel in practical CFT structural engineering.

\section{Experimental program}

\subsection{Specimen details}

Seventeen specimens were designed with different parameters, including three section forms $(120 \times 100 \mathrm{~mm}, 180 \times 120 \mathrm{~mm}, 243 \times 135 \mathrm{~mm})$ with a different aspect ratio $(h / b=1.2,1.5,1.8)$ and width-to-thickness ratio $(h / t$ $=15,22.5,30.5$ ), three kinds of concrete condition (without concrete, C40,
C50), and two nominal eccentricity ratios $\left(\eta=2 e_{0} / h=0.2,0.4\right)$. All specimens were named by the form of "steel-concrete strength-tube section-eccentricity ratio", for instance, the first S in SC40SB-0.2 refers to Q420B high-strength steel, C40 represents C40 grade concrete, SB expresses section $\mathrm{B}(180 \times 120 \mathrm{~mm})$, and 0.2 denotes that the nominal eccentricity ratio is 0.2 . Detailed information about the specimens is listed in Table1. The symbols $e_{0}$ represents eccentric distance measured before the experiment, while $\alpha_{s}$ means the nominal proportion of load bore by steel tubes, which could be calculated through Eq. (1). The slenderness ratio about the principal $x$ axis ( $\lambda$ ) could be obtained through Eq. (2) and Eq. (3).

$\alpha_{s}=\frac{f_{\mathrm{y}} \mathrm{A}_{\mathrm{s}}}{f_{\mathrm{y}} \mathrm{A}_{\mathrm{s}}+f_{\mathrm{c}} \mathrm{A}_{\mathrm{c}}}$

$\lambda=l_{o x} / i_{x}$

$i_{x}=\sqrt{\frac{I_{s x}+I_{c x} E_{\mathrm{c}} / E_{\mathrm{s}}}{A_{\mathrm{s}}+A_{\mathrm{c}} f_{\mathrm{c}} / f_{\mathrm{y}}}}$

In the equations, $f_{\mathrm{y}}$ and $f_{\mathrm{c}}$ refer to the yield strength of steel and compressive strength of concrete. While $E_{\mathrm{s}}$ and $E_{\mathrm{c}}$ represent Young's modulus; $\mathrm{A}_{\mathrm{s}}$ and $\mathrm{A}_{\mathrm{c}}$ refer to the cross-sectional areas where subscript $\mathrm{s}$ and $\mathrm{c}$ represent steel and concrete, respectively. $l_{o x}$ is the effective length about the principal $x$ axis; $I_{s x}$ and $I_{c x}$ are defined as the moment of inertia about principle $x$ axis for the steel section and the concrete section, respectively.

To fabricate the columns, the steel tube of each specimen was assembled by welding four Q420B steel plates. Two cover plates were set onto the end of each steel tube after pouring concrete, as depicted in Fig.2.

Table 1

Detailed information about experimental specimens

\begin{tabular}{|c|c|c|c|c|c|c|c|c|c|c|c|}
\hline Specimen No. & Steel material & Concrete material & $\lambda$ & $h(\mathrm{~mm})$ & $b(\mathrm{~mm})$ & $t(\mathrm{~mm})$ & $\alpha_{s}$ & $h / t$ & $e_{0}(\mathrm{~mm})$ & $N_{\mathrm{u}}(\mathrm{kN})$ & $M_{\mathrm{u}}(\mathrm{kN} \cdot \mathrm{m})$ \\
\hline SC40SA-0.2 & Q420B & $\mathrm{C} 40$ & 22.50 & 123 & 101 & 8 & 0.77 & 15.0 & 14.00 & 1460 & 33.52 \\
\hline SC40SB- 0.2 & Q420B & $\mathrm{C} 40$ & 15.25 & 184 & 120 & 8 & 0.71 & 22.5 & 20.00 & 2375 & 76.67 \\
\hline SC40SE- 0.2 & Q420B & $\mathrm{C} 40$ & 11.45 & 244 & 134 & 8 & 0.67 & 30.4 & 24.50 & 3040 & 93.30 \\
\hline SC50SA-0.2 & Q420B & $\mathrm{C} 50$ & 22.99 & 121 & 101 & 8 & 0.72 & 15.0 & 13.00 & 1590 & 36.00 \\
\hline SC50SB- 0.2 & Q420B & C50 & 15.63 & 180 & 121 & 8 & 0.65 & 22.5 & 20.00 & 2240 & 68.92 \\
\hline SC50SE- 0.2 & Q420B & $\mathrm{C} 50$ & 11.75 & 243 & 134 & 8 & 0.61 & 30.4 & 25.50 & 3260 & 102.53 \\
\hline SC40SA-0.4 & Q420B & $\mathrm{C} 40$ & 22.50 & 121 & 100 & 8 & 0.77 & 15.0 & 25.50 & 1300 & 44.91 \\
\hline SC40SB-0.4 & Q420B & $\mathrm{C} 40$ & 15.25 & 181 & 117 & 8 & 0.71 & 22.5 & 16.50 & 2500 & 59.90 \\
\hline SC40SE-0.4 & Q420B & $\mathrm{C} 40$ & 11.45 & 244 & 135 & 8 & 0.67 & 30.4 & 49.75 & 2500 & 158.92 \\
\hline SC50SA-0.4 & Q420B & C50 & 22.99 & 122 & 100 & 8 & 0.72 & 15.0 & 25.50 & 1230 & 42.98 \\
\hline SC50SB- 0.4 & Q420B & $\mathrm{C} 50$ & 15.63 & 181 & 120 & 8 & 0.65 & 22.5 & 36.00 & 1895 & 107.66 \\
\hline SCOSA- 0.2 & Q420B & - & 21.47 & 121 & 99 & 8 & 1.00 & 30.4 & 11.50 & 1310 & 24.092 \\
\hline SCOSB- 0.2 & Q420B & - & 14.61 & 181 & 120 & 8 & 1.00 & 15.0 & 17.00 & 1850 & 71.39 \\
\hline SCOSE- 0.2 & Q420B & - & 11.04 & 243 & 133 & 8 & 1.00 & 22.5 & 29.50 & 2230 & 76.44 \\
\hline SC0SA- 0.4 & Q420B & - & 21.47 & 120 & 100 & 8 & 1.00 & 30.4 & 23.00 & 1100 & 36.95 \\
\hline SCOSB- 0.4 & Q420B & - & 14.61 & 180 & 121 & 8 & 1.00 & 15.0 & 13.50 & 1980 & 45.12 \\
\hline SCOSE-0.4 & Q420B & - & 11.04 & 245 & 135 & 8 & 1.00 & 22.5 & 50.50 & 1970 & 107.52 \\
\hline
\end{tabular}

\subsection{Material property test}

The same batch of steel was used in this study and Ref.[18]; thus, the results of material property tests are the same as that in Ref[18], including the mean value of steel yield strength $f_{\mathrm{y}}=423.2 \mathrm{MPa}$, tensile strength $f_{\mathrm{u}}=593.8 \mathrm{MPa}$, elasticity modulus $E_{s}=1.98 \mathrm{GPa}$, yield ratio $f_{\mathrm{y}} / f_{\mathrm{u}}=0.71$, percentage elongation after fracture $\Delta=27.18$ and yield strain $\varepsilon_{\mathrm{y}}=2315$.

As for the concrete, six cubic blocks of C40 and C50 concrete were compared with that of experimental specimens after casting and curing in the same environment. The mean value of the cubic strength of concrete C40 and C50 is $43.2 \mathrm{MPa}$ and $55.3 \mathrm{MPa}$.

\subsection{Eccentric compression experiment equipment}

As seen in Fig. 2(a)-(b), two steel bars were welded onto each cover plate to locate the loading line, which is the middle line between these two steel bars The eccentric distance $e_{0}$ equals to the distance between the middle line of the specimen section and the loading line. Knife-edges could be stuck between the two steel bars; therefore, different eccentricity could be applied through the various locations of knife-edge, as shown in Fig. 3.

A NYL-500 5000kN long-column hydraulic compression machine was employed to apply compression loads. Pin constraints were simulated by the knife-edge supports set on both sides of the specimens, as demonstrated in Fig. 3. The arrangement of measurement equipment is presented in Fig. 4. Five 
linear variable displacement transducers (LVDT1-LVDT5) were installed along the column to measure the lateral deflections, while the other four (LVDT6-LVDT9) were used to test the axial displacement. The total of twelve strain gauges at the mid-height cross-section of each specimen were utilized to monitor the longitudinal and lateral strains, four of which were respectively set on flange B and flange $\mathrm{D}$, six were set on the web A and two were attached to web C.

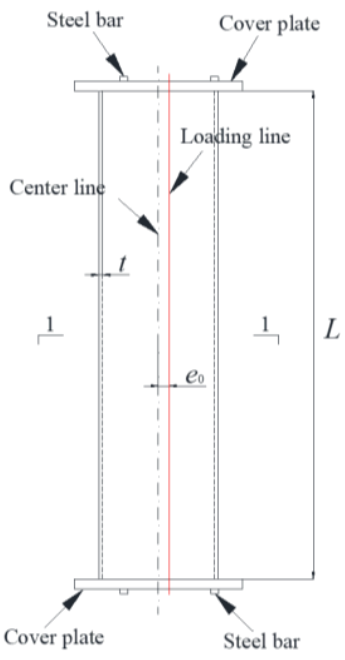

(a) Front view of a specimen

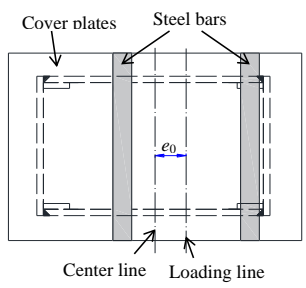

(b) Top view of specimen Butt weld

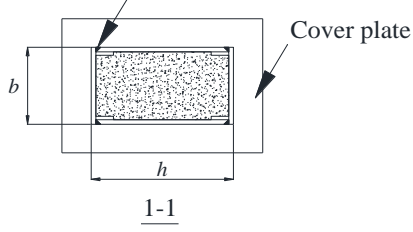

(c) View of 1-1 section
Fig. 2 Illustration of experimental specimen

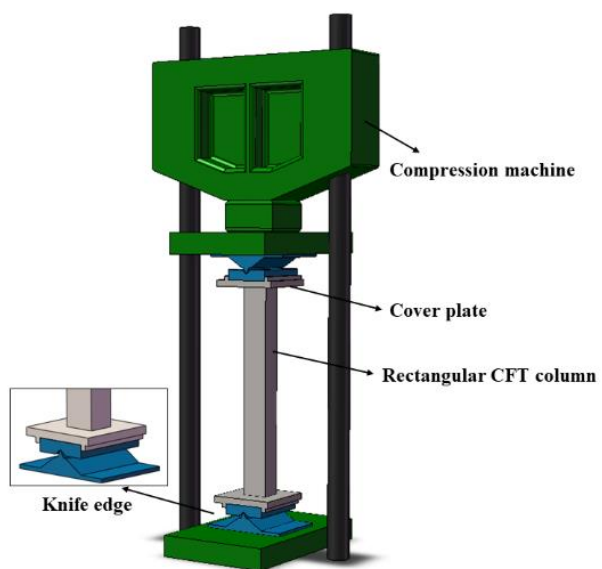

Fig. 3 Experimental apparatus
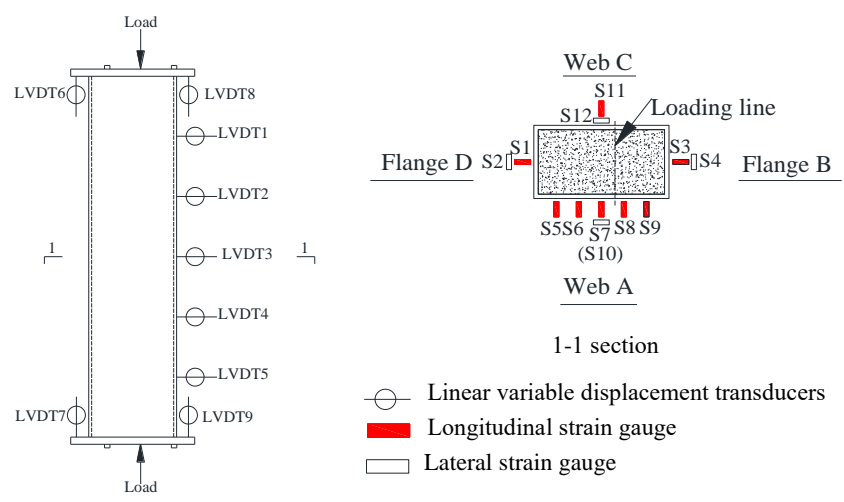

$1-1$ section

Linear variable displacement transducers

Longitudinal strain gauge

$\square$ Lateral strain gauge

Fig. 4 Arrangement of measurement equipment

The multi-stage loading method, with the meaning of applying load at $50 \mathrm{kN}$ intervals, was adopted to record experimental data including the load, strain, and displacement during the experimental process. Besides, both buckling and fracture of steel tubes were observed and recorded

\section{Experimental results}

\subsection{Failure modes}

As shown in Fig.5, all specimens experienced lateral bending failure. This confirms that both local buckling and steel tube fracture occurred with concrete crushing of specimens with SB and SE parts at the same location. Presenting a significant correlation with initial imperfection, in the center of tubes the local buckling did not occur all the time. In general, fracture occurred at the corner, which due to welding is close to the heat - affected zone. It is known that not only outward buckling but inward buckling occurred in the hollow steel columns, which showed that concrete increases the ability of resistance by preventing local steel tube buckling. Typical phenomena, including local steel web and flange buckling, concrete crushing (concrete approaches fault strain), and steel tube fracturing, are described in load - vertical displacement curves, as shown in Fig. 6.
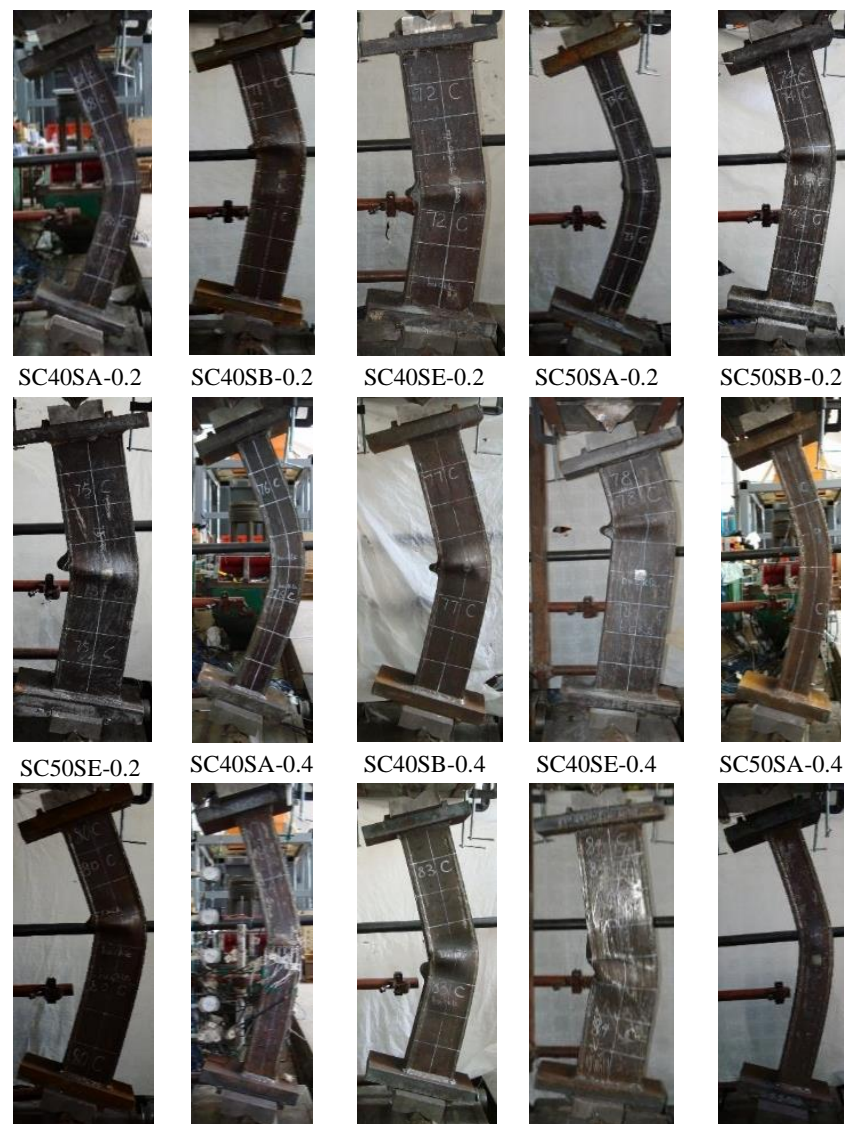

SC40SE-0.4
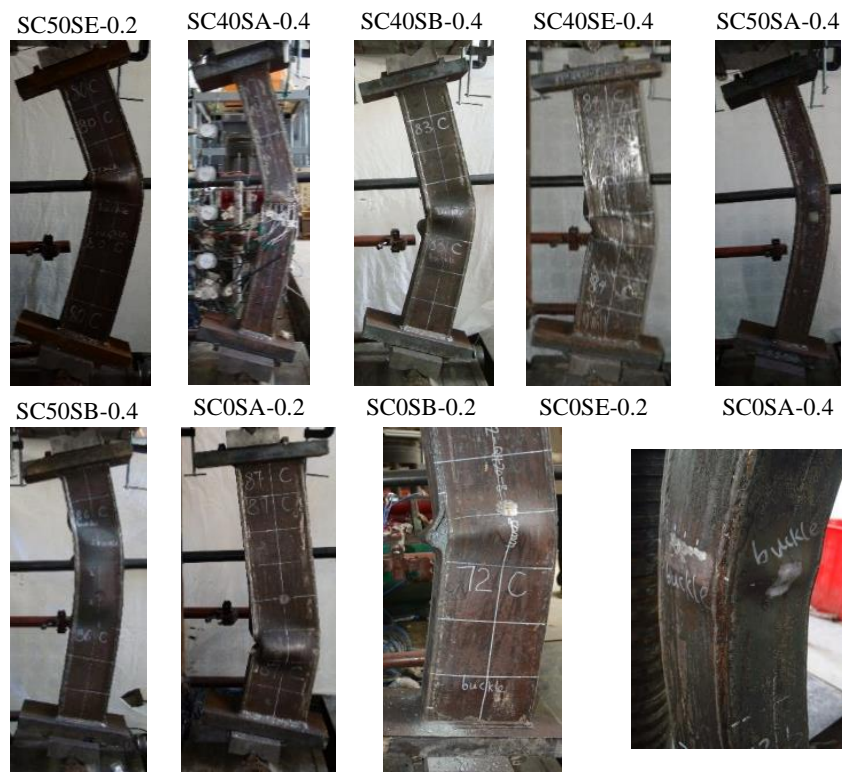

SCOSB- 0.4

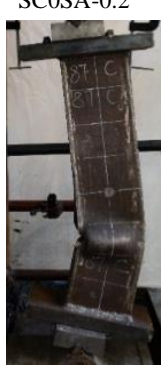

SCOSE- 0.4

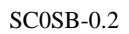

SCOSE- 0.2

SCOSA- 0.4
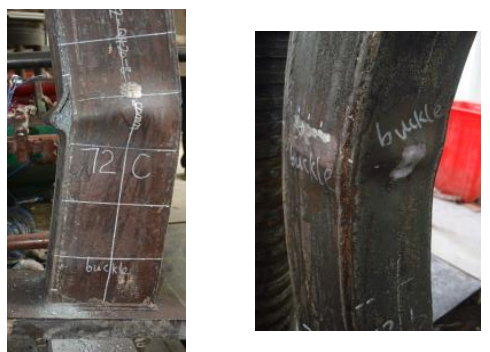

Fracture of steel tube

Buckling of steel tube

Fig. 5 Failure of the specimens

\subsection{Load versus axial shortening behaviors and load versus lateral deformation behaviors}

The curves of load-vertical displacement and load-lateral deflection curves are shown in the Fig. 6 and Fig.7, respectively. These figures indicate that the RCFT columns under eccentric loads have three working stages, namely the elastic linear stage, the elasto - plastic stage, and the post - peak recession phase. Curves through Fig. 6 prove that with section dimension growth, initial axial stiffness and ultimate axial load generally increase signif- 
icantly. The eccentric distance between SC40SB-0.4 and SCOSB-0.4 is smaller than the intended value due to fabrication error. Therefore, the ultimate axial loads of specimens with the SB section are identical to those of specimens with 0.4 eccentricity ratio in the SE section. As shown in Fig.7, the slope of the curves in the elastic stage of all specimens remains basically unchanged. Due to the higher aspect ratio, specimens in SE parts have greater flexural stiffness. Specimens with smaller sections show better ductility, due to the higher slenderness ratio.
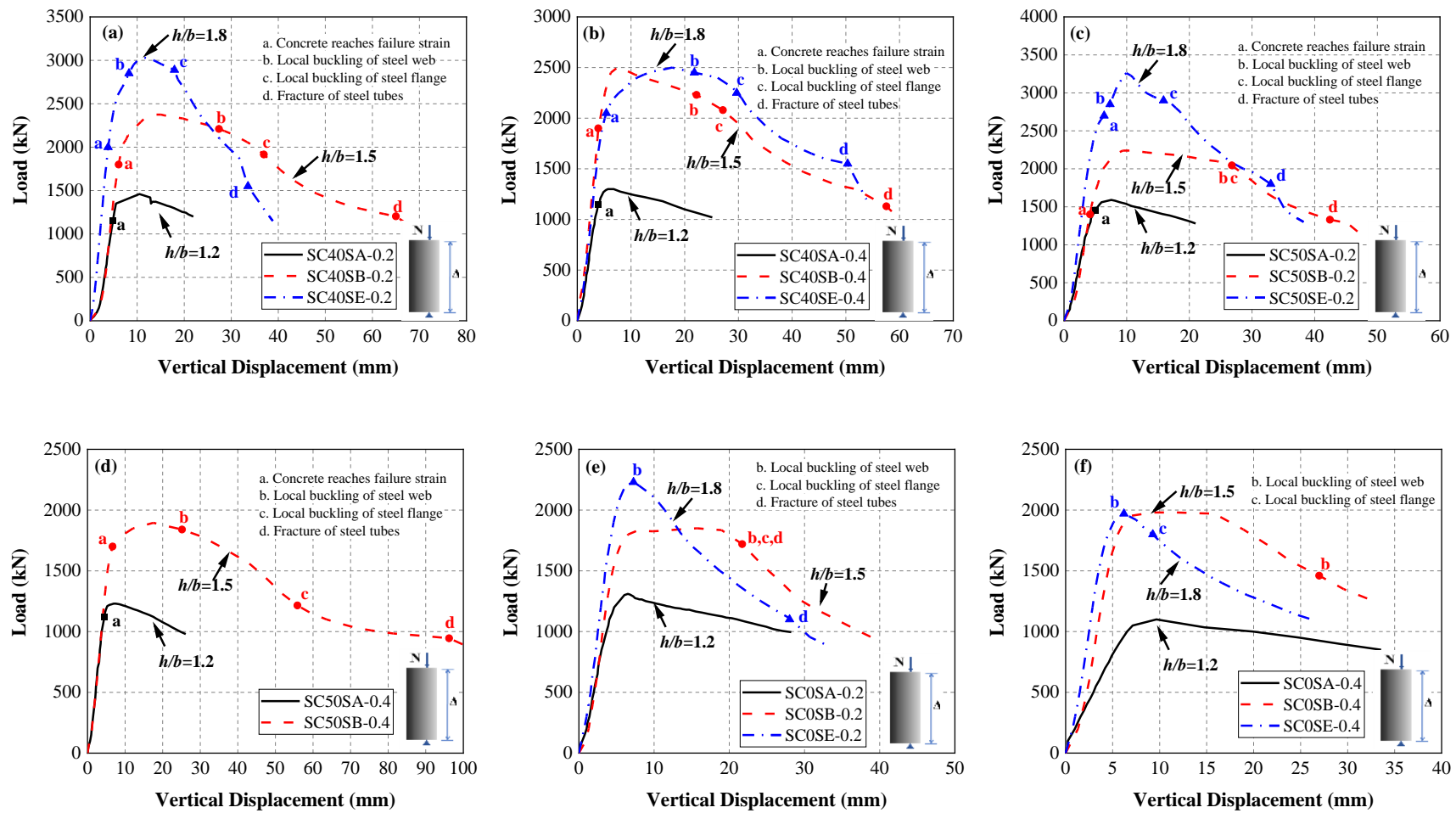

Fig. 6 Load-vertical displacement relationship of specimens
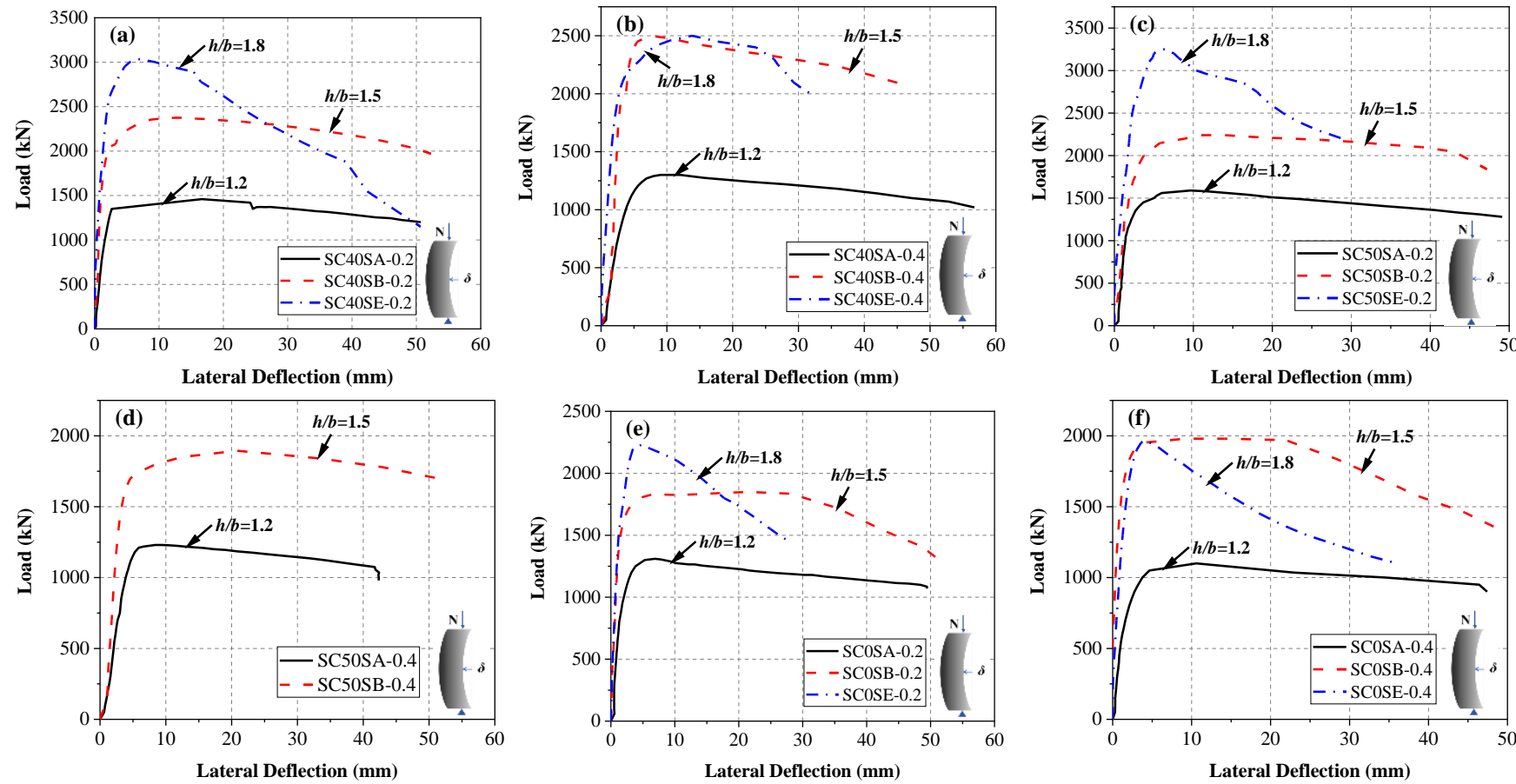

Fig. 7 Load-lateral deflection variations of specimens

\subsection{Load versus strain behaviors}

Typical flange and web A load-strain relationships of the specimens SC40SA-0.2, SC40SB-0.2, SC40SE-0.2, SC40SA-0.4, SC0SA-0.2, and SC50SA-0.2 are shown in Fig. 8 and Fig.9 respectively. Those six specimens included all the variables, namely the different sections, the eccentricity ratios and the strength of concrete. Other specimens produced similar load-strain rela-tionships; thus, they weren't shown here. The flange D of all specimens is under stress before reaching the ultimate condition which could be obtained from the variation of the longitudinal strain S1, as shown in Fig.8. The value of S1 dropped rapidly after attaining the ultimate load. Before the ultimate load for SC40SA-0.4, the S1 strain approximates to zero, which means that S1 is located near neutral axis. The S3 variance shows that flange B has approached yield before the final state.

As presented in Fig.9, the strains of web A developed yielding after 0.6 $N_{\text {u }}$ for most specimens, while the web A was in the elastic stage before 0.8 $N_{\mathrm{u}}$ for SC40SA-0.4. The strains measured by S5-S9 show a linear relationship before yielding. The trend of strains changed at $N_{\mathrm{u}}$ because of the occurrence of local buckling. 


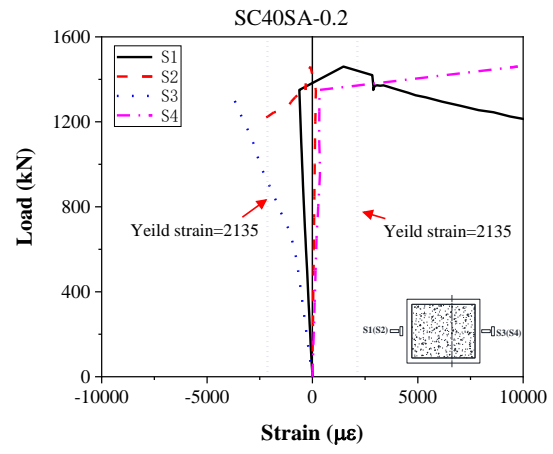

(a)

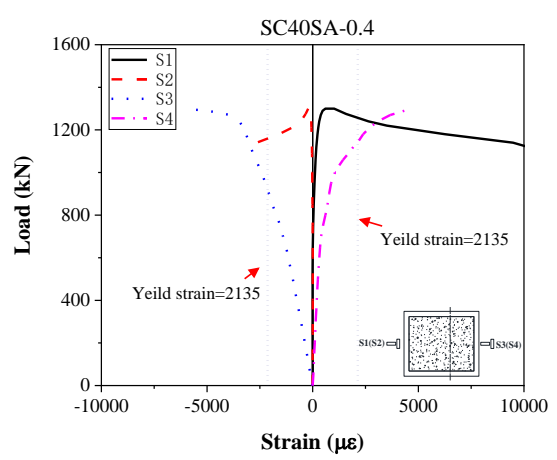

(d)

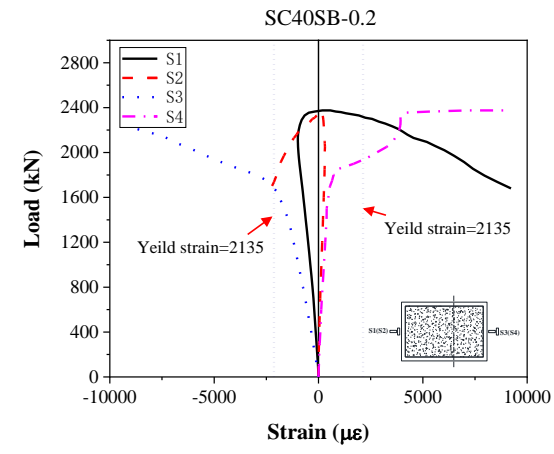

(b)

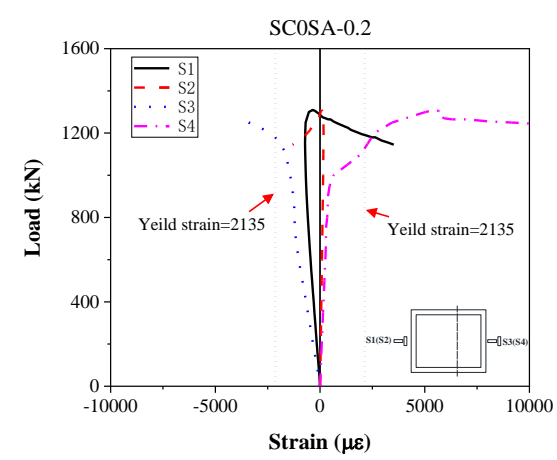

(e)

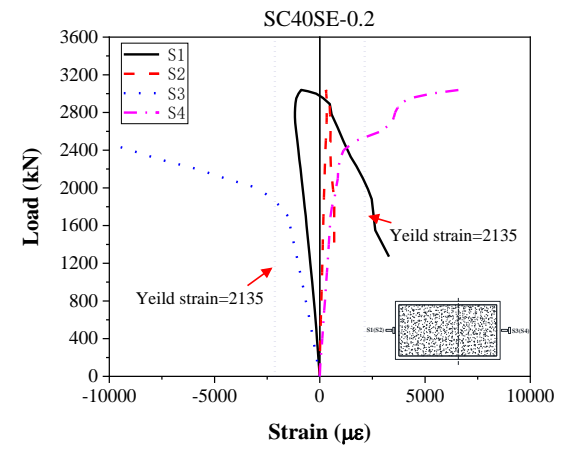

(c)

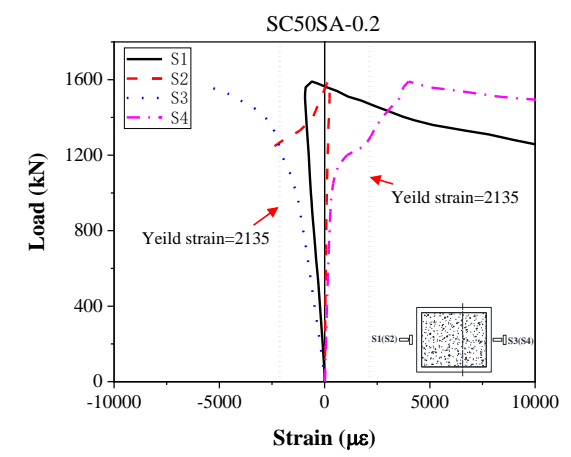

(f)

Fig. 8 Variations of strains on the flanges (S1-S4)

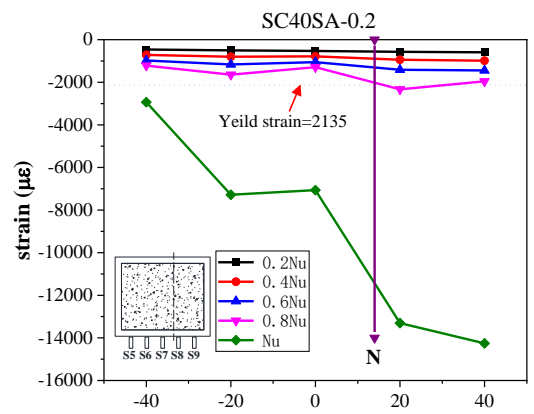

Distance to central axis of web A (mm)

(a)

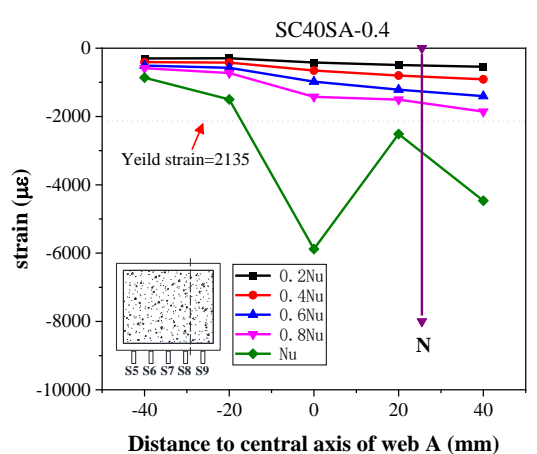

(d)

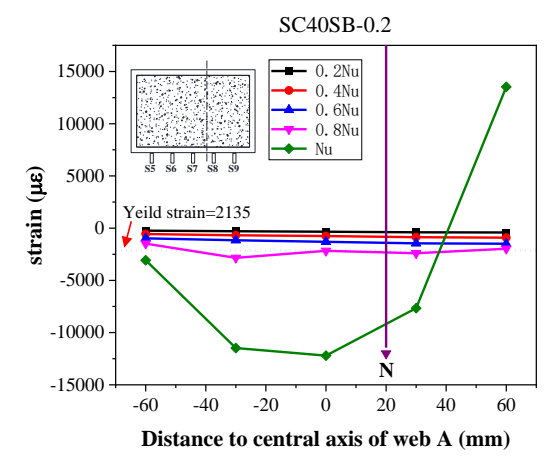

(b)

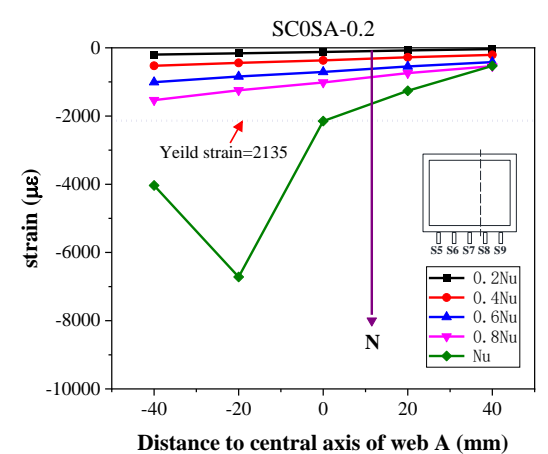

(e)

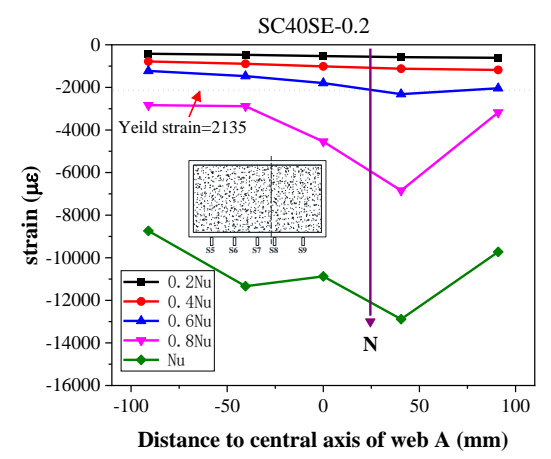

(c)

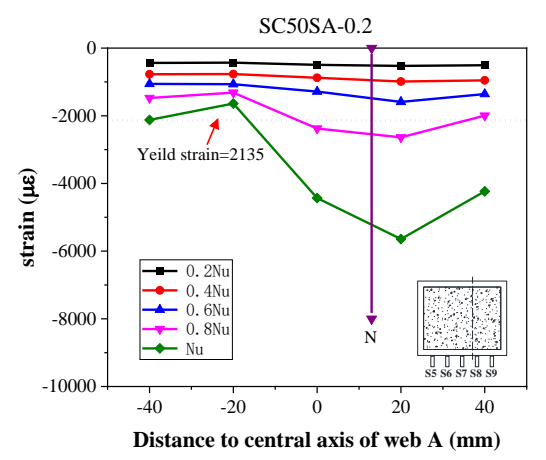

(f)

Note: the arrows refer to the actual eccentricity location of the load $\mathrm{N}$

Fig. 9 Variations of longitudinal strains on the web A (S5-S9)

\subsection{Ultimate resistance}

Test ultimate compressive resistance, including ultimate axial load $N_{\mathrm{u}}$ and ultimate bending moment $M_{\mathrm{u}}$, is listed in Table 1 . The value $N_{\mathrm{u}}$ is directly obtained from experimental data, whereas $M_{\mathrm{u}}$ the sum of the moment and secondary moment is calculated through equation (4), where $\delta$ refers to the max lateral deflection recorded by LVDT1 to LVDT5.

$$
M_{\mathrm{u}}=N_{\mathrm{u}} e_{0}+N_{\mathrm{u}} \delta
$$

\subsection{Discussions}

\subsubsection{Effect of in-fill concrete}

The in-fill concrete strength influences not only the failure modes but also 
the ultimate specimen capacity, as seen in Fig.5 and Fig.10. Comparing hollow steel tube column failure modes with those of CFT columns, it can be found that in-fill concrete could increase resistance ability to local buckling of steel tubes. The ultimate axial load $N_{\mathrm{u}}$ of SC40SA-0.2, SC40SB-0.2, and SC40SE-0.2 increase $11.5 \%, 28.4 \%$, and $36.3 \%$, respectively, compared with SCOSA-0.2, SCOSB-0.2, and SCOSE-0.2, which indicated that in-fill concrete improves the bearing capacity of columns remarkably in higher $h / b$ and $h / t$. However, there were few changes in the bearing capacity when the grade of concrete increases from C40 to C50. From Fig.10(a) and Fig.10(b), it is worth noting that the percentage of bearing capacity raise become smaller as $\eta$ changes from 0.2 to 0.4 .

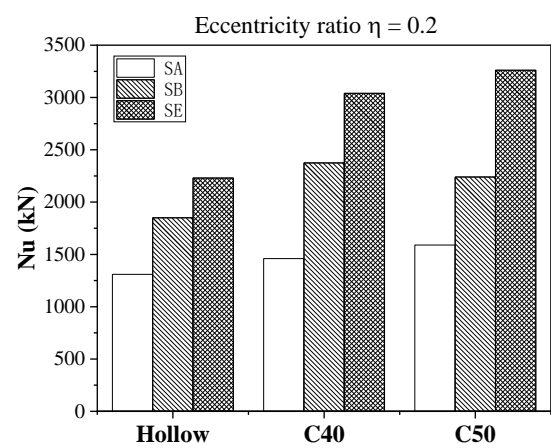

(a)

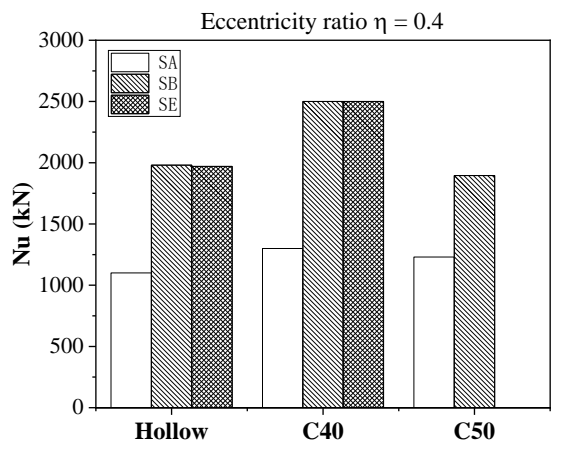

(b)

Fig. 10 Effect of in-fill concrete

\subsubsection{Effect of width-to-thickness ratio $h / b$}

Normalized ratios $M_{\mathrm{u}} / M_{\mathrm{c}}$ and $N_{\mathrm{u}} / N_{\mathrm{c}}$ are calculated to analyze the effect of width-to-thickness ratio $h / b$, where $M_{\mathrm{c}}$ and $N_{\mathrm{c}}$ refer to the bending moment and design axial load calculated by one of Chinese codes DB 29-57[30], respectively. All normalized ratios are larger than one, which indicated that using DB 29-57 to design RCFT columns fabricated with Q420 HSS will get a safer result. As presented in Fig. 11(a) and (b), when $\eta=0.2$, with the growth in $h / b$, the value of $N_{u} / N_{c}$ increased from 1.25 to 1.4 and the value of $M_{\mathrm{u}} / M_{\mathrm{c}}$ undergone an approximate process of linear decline. Figure. 11(c) and (d) show that the value of $N_{u} / N_{c}$ and $M_{u} / M_{c}$ changed little with the improvement of $h / b$ on the columns when $\eta=0.4$. It indicates in the study that $h / b$ has a little influence on $N_{\mathrm{u}} / N_{c}$ when it is smaller than 30.5. Thus, DB 29-57 tends to be less conservative with higher $h / b$ according to the variation trends of $M_{\mathrm{u}} / M_{\mathrm{c}}$ as displayed in Fig. 11(b).

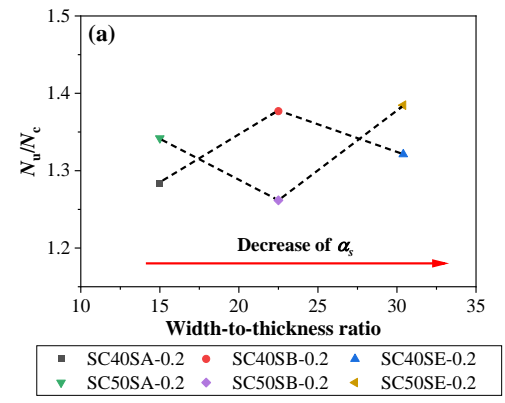

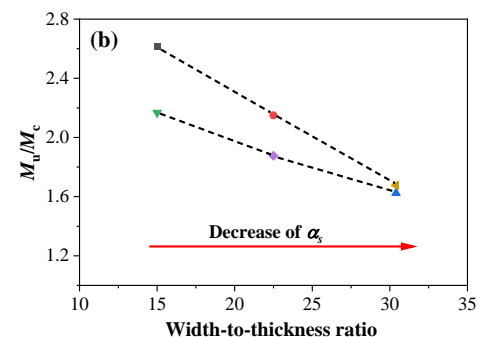

- SC40SA-0.2 * SC40SB-0.2 $\triangle$ SC40SE-0.2 $\checkmark$ SC50SA-0.2 + SC50SB- 0.2 \&C50SE- 0.2

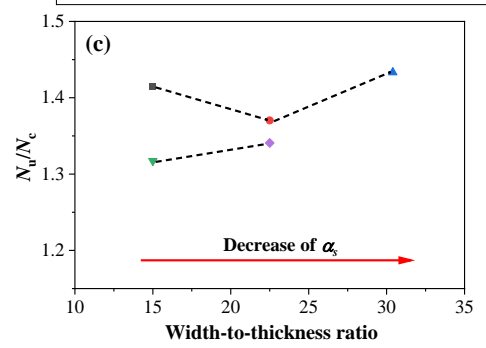

SC40SA-0.4 $\quad$ SC40SB-0.4 $\triangle$ SC40SE- 0.4 $\rightarrow$ SC50SA-0.4 $\quad$ SC50SB-0.4

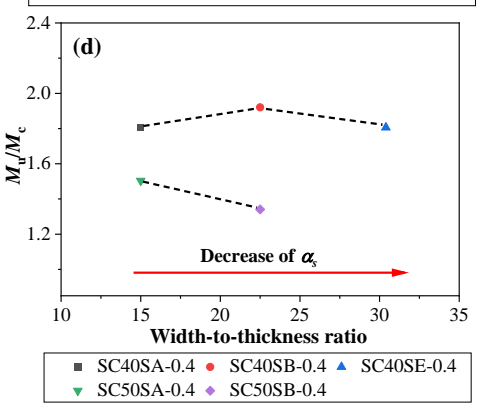

Fig. 11 Influence of width-to-thickness ratio

\subsubsection{Effect of eccentricity ratio $\eta$}

The effect of the eccentricity ratio $\eta$ on the behaviors is estimated by analyzing the comparison result of SC40SB- 0.2 with SC40SB-0.4. Figure 12 depicts the load versus vertical displacement curves. With $\eta$ increasing from 0.2 to 0.4 , the value of $N_{\mathrm{u}}$ dropped $160 \mathrm{kN}$, while $M_{\mathrm{u}}$ increased $0.15 \mathrm{kN} \cdot \mathrm{m}$. The load dropped slower after the ultimate state for the columns with a relatively higher eccentricity ratio. According to this, the ductility of RCFT columns may be improved when undergoing a higher eccentricity ratio.
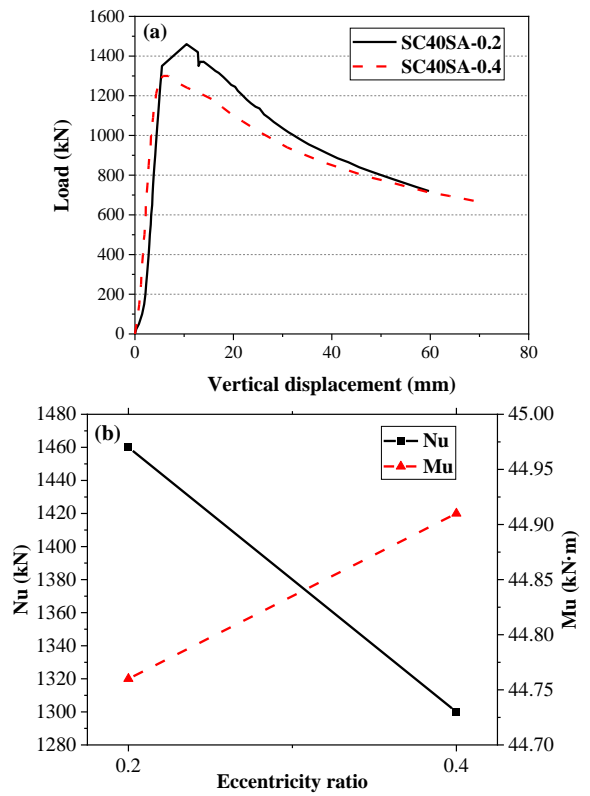

Fig. 12 Effect of eccentricity ratio

\section{Finite element analysis}

4.1. Analytic model 
ABAQUS software was utilized to establish the FE models for the aim of analyzing the behavior of RCFT columns during the eccentric loading process. The entire specimen was simulated, including the cover plate and the knife-edge, and the general view of a model is depicted in Fig.13(a). Eight-node reduced integration brick element (C3D8R), and four-node thick reduced integration shell element (S4R) were chosen to model in-fill concrete and steel tubes respectively, as shown in Fig.13(b). A mesh size of $h / 10$ can achieve relatively precise results with the minimum computational cost for most of the specimens according to mesh sensitive analysis result. Loading lines on the top and bottom were coupled to two reference points, respectively, as seen from Fig.13(c). All degrees of freedom of RP1 and RP2 were restrained except rotation around the $\mathrm{Y}$ axis and displacement in the $\mathrm{Z}$ direction of RP1.

Regarding the Q420B steel material stress - strain model, the simpler bilinear model, regardless of strain-hardening, was adopted according to Ref[28]. Elasticity modulus $E_{s}$ and yield strength $f_{\mathrm{y}}$ values were set in accordance with the tested values in Section 2.2. As for in-fill concrete in this study, the stress-strain model proposed by Han [31] and the damaged plastic model were adopted into the simulation. The values of key parameters in damaged plastic model are listed in Table 2 .

Table 2

Key parameters value in damaged plastic model

\begin{tabular}{ll}
\hline Parameter & Value \\
\hline Dilation angle $(\psi)$ & $20^{\circ}$ \\
Flow potential eccentricity $\left(e_{f}\right)$ & 0.1 \\
Biaxial compression strength to uniaxial compression & 1.13 for C40 \\
strength of concrete $\left(f_{b 0} / f_{c 0}\right)$ & 1.11 for C50 \\
Ratio of the second stress invariant on the tensile meridian & 0.719 for C40 \\
to that on the compressive meridian $(K)$ & 0.714 for C50 \\
Viscosity parameter $(v)$ & 0 \\
\hline
\end{tabular}

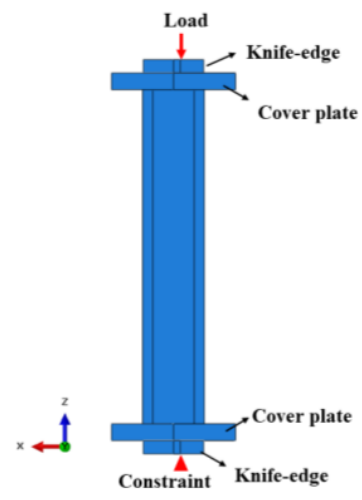

(a) General view of FE model

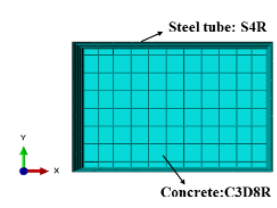

(b) Mesh of the model

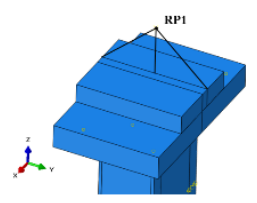

(c) Reference point
Fig. $13 \mathrm{FE}$ model of the specimen

The interface of concrete and steel tube was set as surface-to-surface contact. A "hard contact" was used in the normal direction, which permits separation in tension together with nonpenetration in compression. In contrast, in the tangential direction, Coulomb friction was applied with friction factor 0.25, according to Ellobody and Young[23]. In order to consider the influence of initial imperfection, an initial imperfection with the value of $L / 1000$ is applied for all specimens. The shape of imperfection was regarded as the first mode acquired by an eigenvalue buckling analysis, which contains both global and local buckling.

\subsection{Validations}

The mode of failure of the whole columns is similar to that of experimental results. Figure 14 presents a comparison of typical failure mode between the FE analysis and the experiment for the specimen SC40SB-0.2. The FE predicted ultimate axial load $N_{\mathrm{FE}}$, the corresponding ultimate moment $M_{\mathrm{FE}}$, calculated value $N_{\mathrm{u}} / N_{\mathrm{FE}}$ and $M_{\mathrm{u}} / M_{\mathrm{FE}}$ are given in Table $3 . \mathrm{FE}$ analysis results match well with experimental data, where the mean value and standard deviation $N_{\mathrm{u}} / N_{\mathrm{FE}}$ and $M_{\mathrm{u}} / M_{\mathrm{FE}}$ are $0.999,0.936,0.041$, and 0.032 , respectively.

The FE predicted load-vertical displacement curves and load-lateral deflection curves compared to the experimental curves of SC40SA-0.2, SC40SB-0.2, SC40SE-0.2, SC40SA-0.4, SC0SA-0.2, and SC50SA-0.2 are presented in Fig.15 and Fig.16. All curves obtained through FE analysis show good agreement with that from the experiment before the failure, which indicates that the FE models proposed in this study could be utilized to simulate the rectangular columns with Q420B high-strength steel tubes.
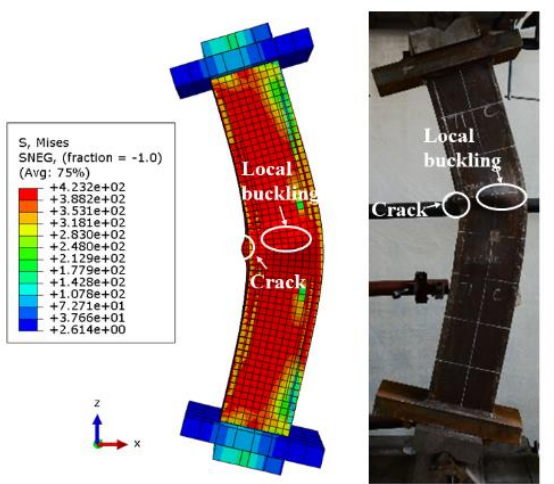

Fig. 14 Failure mode comparisons between FE analysis and experiment of SC40SB-0.2

Table 3

FE analysis results and the comparison with the experimental results

\begin{tabular}{lcccc}
\hline Specimen No. & $N_{\mathrm{FE}} / \mathrm{kN}$ & $M_{\mathrm{FE}} /(\mathrm{kN} \cdot \mathrm{m})$ & $N_{\mathrm{FE}} / N_{\mathrm{u}}$ & $M_{\mathrm{FE}} / M_{\mathrm{u}}$ \\
\hline SC40SA-0.2 & 1545.515 & 30.254 & 1.058 & 0.903 \\
SC40SB-0.2 & 2392.000 & 70.266 & 1.007 & 0.917 \\
SC40SE-0.2 & 3017.030 & 90.430 & 0.992 & 0.969 \\
SC50SA-0.2 & 1621.261 & 32.245 & 1.020 & 0.900 \\
SC50SB-0.2 & 2451.37 & 63.370 & 1.094 & 0.919 \\
SC50SE-0.2 & 3174.300 & 93.891 & 0.974 & 0.916 \\
SC40SA-0.4 & 1277.542 & 43.743 & 0.983 & 0.974 \\
SC40SB-0.4 & 2482.421 & 56.430 & 0.993 & 0.942 \\
SC40SE-0.4 & 2409.730 & 143.159 & 0.964 & 0.901 \\
SC50SA-0.4 & 1327.032 & 43.578 & 1.079 & 1.014 \\
SC50SB-0.4 & 1879.782 & 98.856 & 0.992 & 0.918 \\
SC0SA-0.2 & 1291.244 & 22.683 & 0.986 & 0.942 \\
SC0SB-0.2 & 1765.331 & 64.612 & 0.954 & 0.905 \\
SC0SE-0.2 & 2170.81 & 70.268 & 0.973 & 0.919 \\
SC0SA-0.4 & 1118.162 & 34.239 & 1.007 & 0.926 \\
SC0SB-0.4 & 1849.750 & 43.104 & 0.934 & 0.955 \\
SC0SE-0.4 & 1929.465 & 105.978 & 0.979 & 0.986 \\
Mean value & & & 0.999 & 0.936 \\
Standard devi- & & & 0.041 & 0.032 \\
ation & & & & \\
\hline
\end{tabular}




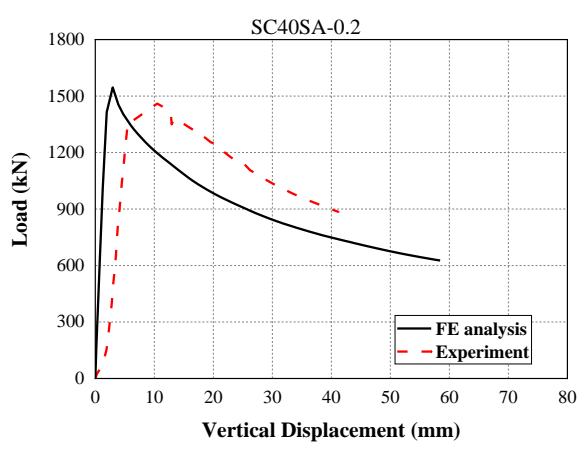

(a)

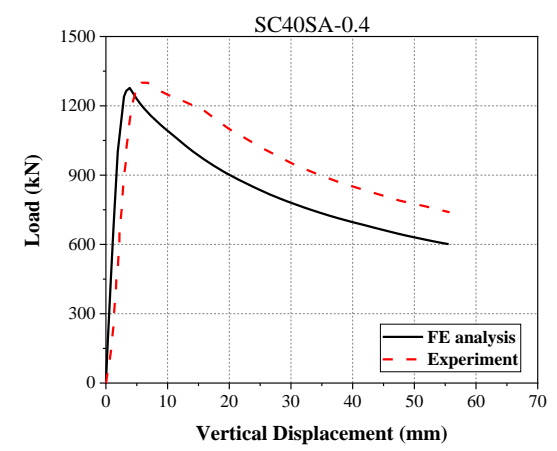

(d)

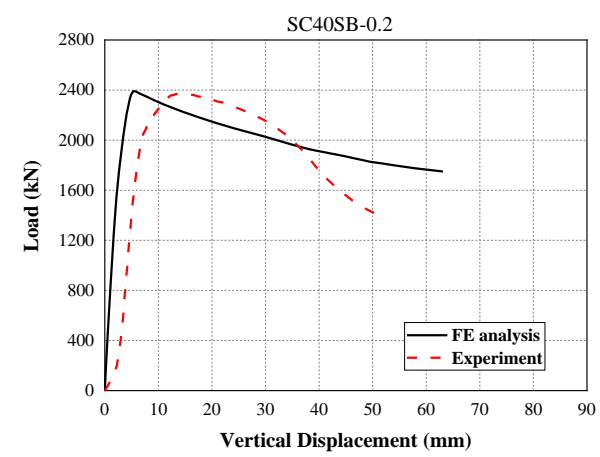

(b)

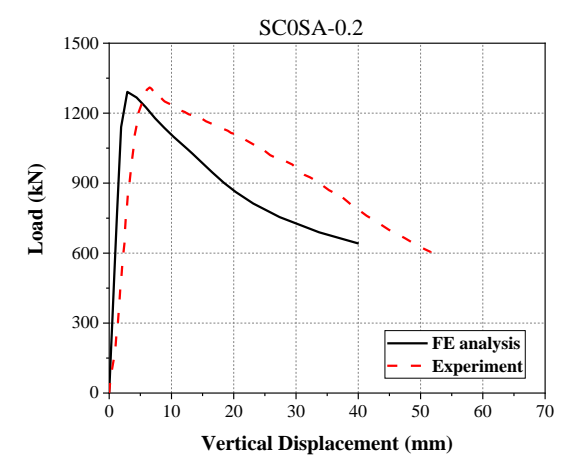

(e)

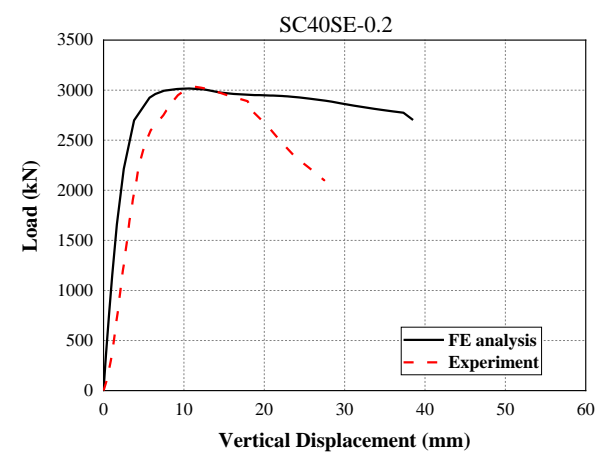

(c)

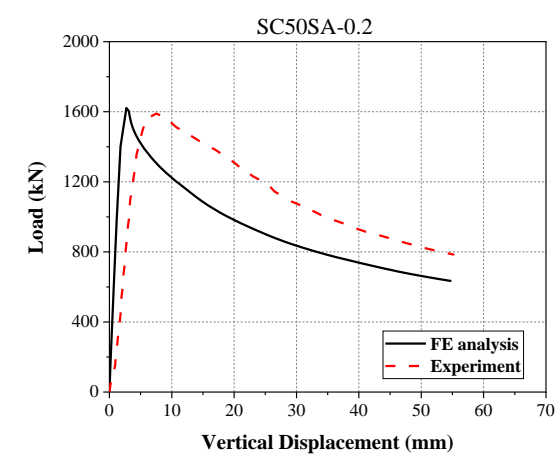

(f)

Fig. 15 Comparison between experiment and FE predicted result in load-vertical displacement curves

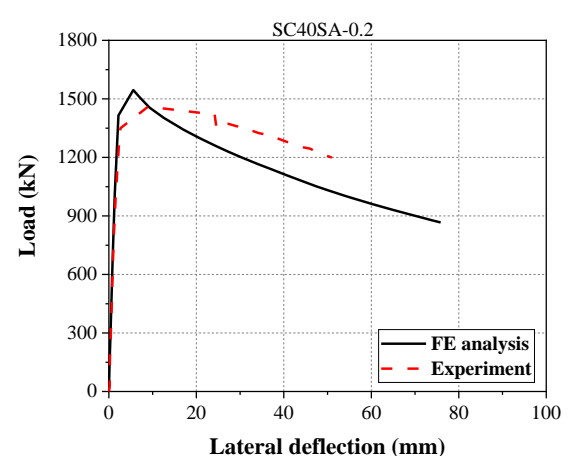

(a)

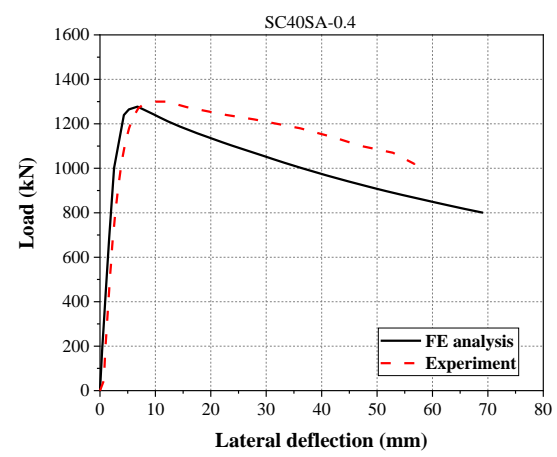

(d)

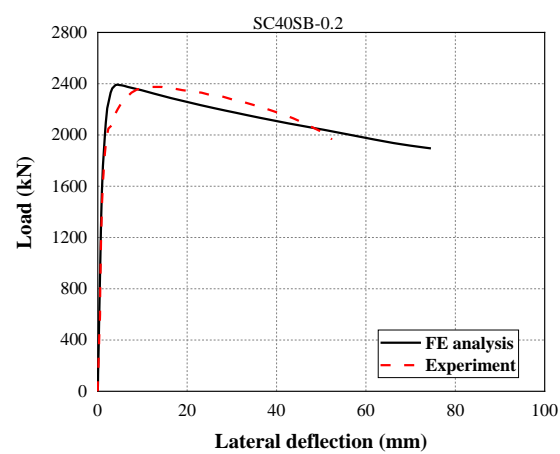

(b)

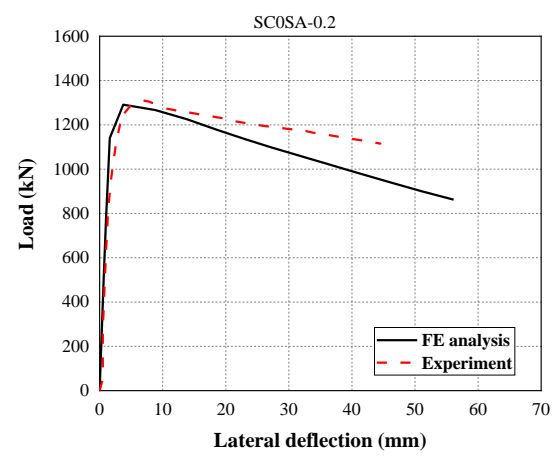

(e)

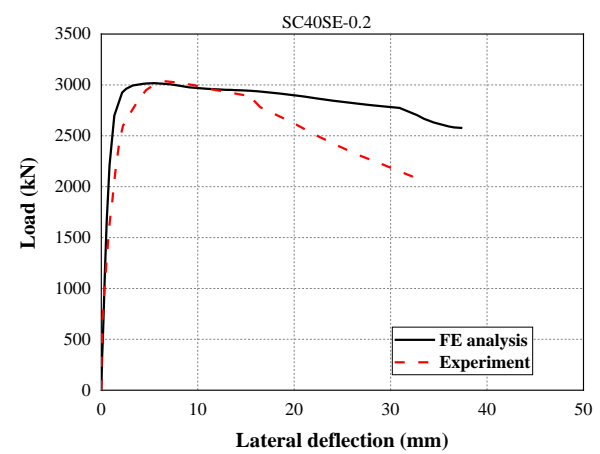

(c)

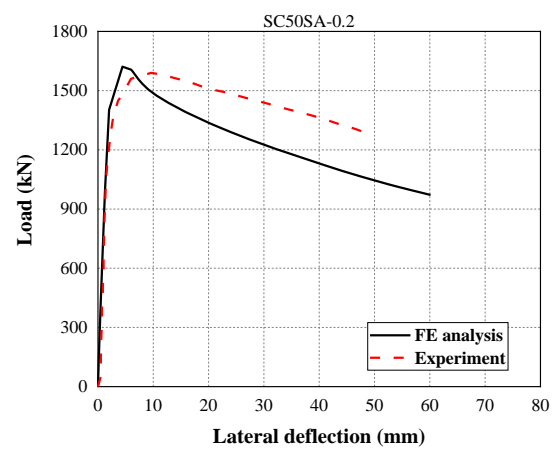

(f)

Fig. 16 Comparison between experiment and FE predicted load-lateral deformation curves

\section{Evaluation of design codes and proposed design approach}

\subsection{Evaluation of the current design codes}

At present, a series of design specifications about composite structures have been widely used in different countries, for instance, European code (EC4[32]), Specification for Structural Steel Buildings in America (AISC360[33]), AIJ[34] in Japan, GB 50936-2014[35] and DB 29-57[30] in China, et al. In the above-mentioned codes, which are based on the resistance interaction curves, namely N-M interaction curves, the method of calculating bearing capacity of RCFT beam - columns under compression and bending was stipulated. In order to verify the applicability of these codes, the N-M interaction curves determined by design equations were compared to the experimental results which can be seen in Fig.17. The green points represent the bearing capacities of the specimens with the meaning of the ultimate axial loads and the corresponding bending moments.

As shown in Fig.17, all the abovementioned codes are conservative in predicting the bearing capacities of RCFT columns fabricated with Q420B HSS in this paper. The results calculated by EC4, AISC360, and AIJ are close to each other, while the results from GB 50936 and DB 29-57 are much more conservative, especially GB 50936 provides the most conservative results for the columns with $h / t=1.2$ and $h / b=15$. With the raising of $h / b, h / t$ and concrete strength, the results obtained from experiments are closer to but consistently higher than the predicted results from design codes. Too con- 
servative design leads to a waste of building materials and an increase in the project costs. Thus it is necessary to propose more accurate approaches and revise the design codes in China for designing RCFT columns incorporating HSS.

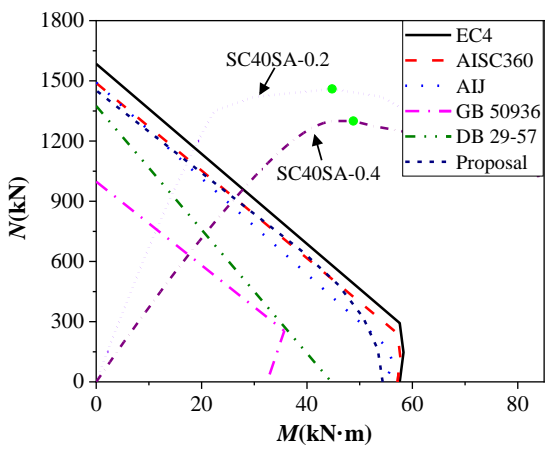

(a)

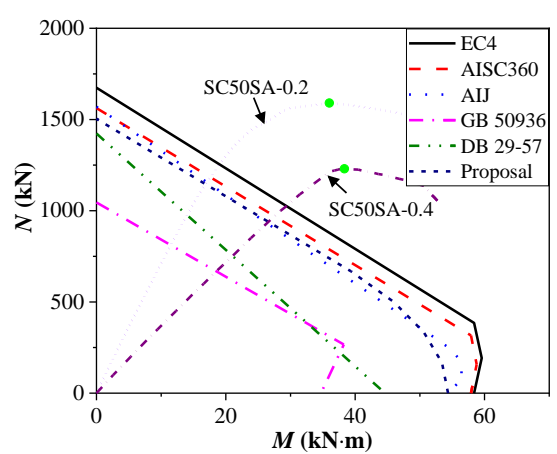

(d)

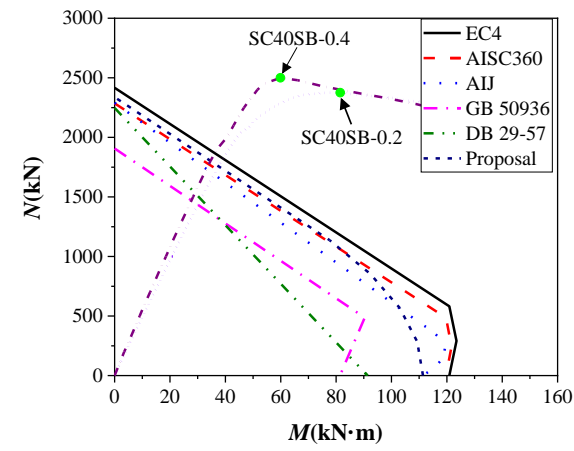

(b)

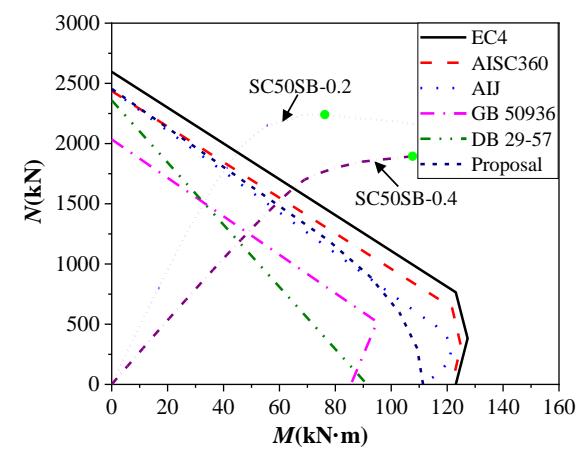

(e)

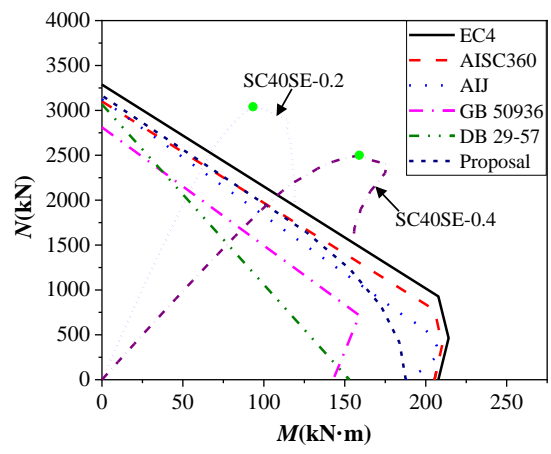

(c)

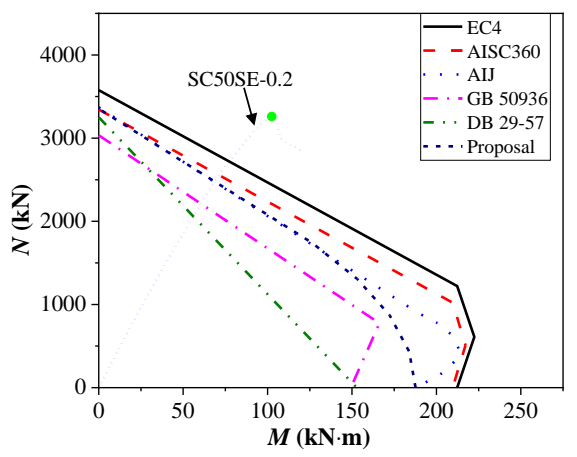

(f)

Fig. 17 Comparison of N-M interaction curves

\subsection{Proposed design approach and validation}

As quantitatively analyzed in Ref [27], the steel tubes in RCFT columns fabricated with HSS undertake most load because of higher steel strength and higher steel ratio. Chinese design code DB 29-57 assumes that part of axial loads and all bending moments are bored by the steel tubes, while the concrete bears only part of axial loads. The above assumptions are particularly suited for designing RCFT columns fabricated with HSS. The test results show that majority of steel webs could develop yielding before buckling when approaching the ultimate load; hence, the fully-plastic state could be assumed as the ultimate state of the CFT columns, as shown in Fig.18.

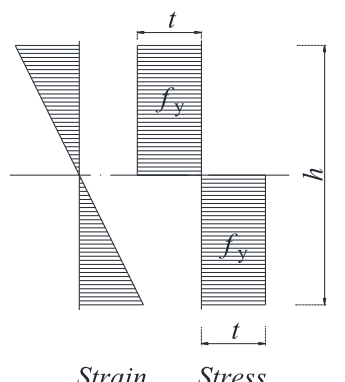

Fig. 18 Fully-plastic state of steel web

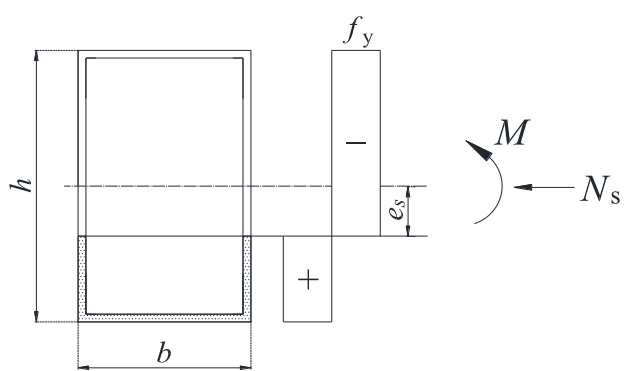

(a) $0 \leq e_{s}<h / 2-t$

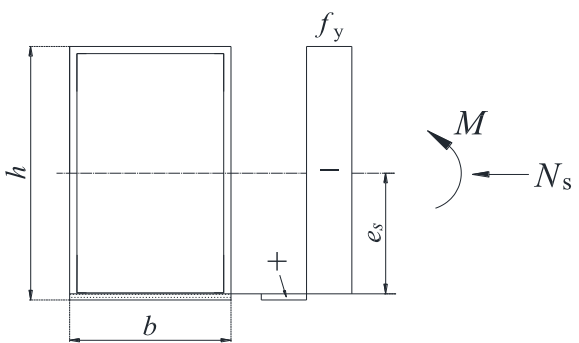

(b) $h / 2-t \leq e_{s} \leq h / 2$

Fig. 19 Stress blocks of steel tubes

The stress blocks to calculate the ultimate capacity were illustrated in Fig.19. The total bearing capacity could be obtained using the factor $\alpha_{s}$ defined in Eq. (1) as specified in DB 29-57; thus, only the stress of steel tubes was calculated in this study. $e_{s}$ refers to the distance from the centerline to the neutral axis of the cross-section. The stress blocks in Fig.19 are more universal than those presented in Ref [26], which accounts for the influence of the steel backing plates.

The load sustained by the steel $\left(N_{s}\right)$ could be obtained through the integration of the axial stress of the steel. The total axial capacity $N$ could be calculated by the equation $N_{s}=\alpha_{s} \cdot N$. The bending moment $M$ could be obtained in the stress blocks of the steel section, which is around the principal axis. As presented in Fig. 19, when $0 \leq e_{s}<h / 2-t$ the axial capacity $N$ and the corresponding moment $M$ can be calculated according to Eq. (5)-(7):

$N_{\mathrm{s}}=4 f_{\mathrm{y}} e_{s} t$

$N=\frac{4 f_{\mathrm{y}} e_{s} t}{\alpha}$

$M=2 f_{\mathrm{y}} t\left[b(h-t) / 2+(h / 2-t)^{2}-e_{s}^{2}\right]$ 
When $h / 2-t \leq e_{s}<h / 2, N$, and $M$ can be calculated by Eq. (8)-(10):

$N_{\mathrm{s}}=f_{\mathrm{y}}\left[2(h+b) t-4 t^{2}-b\left(h-2 e_{s}\right)\right]$

$N=\frac{f_{\mathrm{y}}\left[2(h+b) t-4 t^{2}-b\left(h-2 e_{s}\right)\right]}{\alpha_{s}}$

$M=f_{\mathrm{y}} b\left(h^{2} / 4-e_{s}^{2}\right)$

The N-M curves were determined through the corresponding moment $M$ and axial force $N$ when $e_{s}$ changes from $h / 2$ to zero. Besides, the reduction factor $\varphi_{x}$ stipulated in DB 29-57 was also introduced in the equations to reflect the influence of the length effect.

A comparison between the experimental results and predictions calculated by the proposed approach is presented in Fig.17. Comparing with the experimental results, the results obtained from the above-proposed N-M design curves are relatively conservative and more precise than GB 50936-2014 and DB 29-57 used in China, but close to the results of EC4, ASIC 360 and AIJ.

\section{Conclusions}

This paper presents a systematic examination to reveal the mechanical behaviors of RCFT columns manufactured with Q420B HSS under excentric load, including experiments, numerical simulation, and theoretical analysis. Seventeen specimens were designed and tested taking into account the impact of concrete strength, cross - section aspect ratios, width to thickness ratios, and eccentricity ratios. In order to reveal the behavior of RCFT columns during the eccentric loading process, nonlinear FE analysis was performed. Comparing experimental results, the criteria GB 50936, DB 29-57, EC4, AISC 360 , AIJ and the proposed approach have been evaluated. The key findings are categorized as follows:

\section{References}

[1] Han L-H, Li W, Bjorhovde R., Developments and advanced applications of concrete-filled steel tubular (CFST) structures: Members, Journal of Constructional Steel Research, 100, 211-228, 2014.

[2] Uy B., Static long-term effects in short concrete-filled steel box columns under sustained loading, ACI Structural Journal, 98(1), 96-104, 2001

[3] Sakino K, Nakahara H, Morino S, Nishiyama I., Behavior of centrally loaded concrete-filled steel-tube short columns, Journal of Structural Engineering. 130(2), 180-188, 2004.

[4] Guler S, Copur A, Aydogan M., A Comparative Study on Square and Circular High Strength Concrete-Filled Steel Tube Columns, Advanced Steel Construction, 10(2), 234-47, 2014.

[5] Du Y, Chen Z, Xiong M., Experimental behavior and design method of rectangular concrete-filled tubular columns using Q460 high-strength steel, Construction and Building Materials, 125, 856-872, 2016.

[6] Hernández-Figueirido D, Romero ML, Bonet JL, Montalvá JM., Ultimate capacity of rectangular concrete-filled steel tubular columns under unequal load eccentricities, Journal of Constructional Steel Research, 68(1), 107-117 2012.

[7] Lai Z, Varma AH, Zhang K., Noncompact and slender rectangular CFT members: Experimental database, analysis, and design. Journal of Constructional Steel Research, 101,455-468, 2014

[8] Lee C, Kang THK, Kim S, Kang K., Strain compatibility method for the design of short rectangular concrete-filled tube columns under eccentric axial loads, Construction and Building Materials, 121, 143-153, 2016.

[9] Long Y, Wan J, Cai J., Theoretical study on local buckling of rectangular CFT columns under eccentric compression, Journal of Constructional Steel Research, 120, 70-80, 2016.

[10] Ding F, Luo L, Zhu J, Wang L, Yu Z., Mechanical behavior of stirrup-confined rectangular CFT stub columns under axial compression, Thin-Walled Structures, 124, 136-150, 2018.

[11] Wang R, Han LH, Nie JG, Zhao XL., Flexural performance of rectangular CFST members, Thin-Walled Structures, 79, 154-65, 2014

[12] Bong Kwon Y, Kyu Jeong I., Resistance of rectangular concrete-filled tubular (CFT) sections to the axial load and combined axial compression and bending, Thin-Walled Structures, 79, 178-186, 2014.

[13] Du Z, Liu Y, He J, Chan S., Direct analysis method for noncompact and slender concrete-filled steel tube members, Thin-Walled Structures, 135, 173-184, 2019.

[14] Shi G, Zhu X, Ban H., Material properties and partial factors for resistance of high-strength steels in China, Journal of Constructional Steel Research, 121, 65-79, 2016.

[15] Wang YB, Lyu YF, Wang YZ, Li GQ, Richard Liew JY., A reexamination of high strength steel yield criterion, Construction and Building Materials, 230, 2020.

[16] Li G, Wang Y, Chen S., Experimental study on ultimate bearing capacity of axially compressed high strength steel columns, Jianzhu Jiegou Xuebao/Journal of Building Structures, 33(3), 8-14, 2012. (in Chinese).
(1) By delaying the occurrence of local buckling of steel tubes, in-fill concrete could effectively enhance the ultimate capacity of columns Considerable difference could be observed between the columns with and without concrete - filling, whereas the concrete grade has a marginal influence, particularly on the one with a larger aspect ratio.

(2) Based on the results of this study, the width-to-thickness ratio has little influence on the ultimate capacity $N_{\mathrm{u}}$ to design axial load $N_{\mathrm{c}}$ calculated through Chinese code DB 29-57 when the value is below 30.5 However, a higher width-to-thickness ratio has disadvantageous effects on the bearing moment $M_{\mathrm{u}}$

(3) The proposed FE models had a reasonable accuracy in predicting the ultimate capacities of RCFT columns made of Q420B HSS. Not only failure modes but load-vertical displacement curves and load-lateral deflection curves also matched the experimental results.

(4) All design codes, including EC4, AISC360, AIJ, GB 50936-2014, and DB 29-57, are conservative when calculating the ultimate capacities of RCFT columns fabricated with Q420B HSS under eccentric loads. GB 50936 and DB 29-57 obtain the most conservative results, while EC4 is relatively the least conservative one. Compared with the current design codes used in China, the calculation method of N-M interaction curves proposed in this paper could obtain much more precise ultimate capacities. Therefore, the proposed approach is recommended to be a reference for future practice.

\section{Acknowledgements}

This work is sponsored by the National Natural Science Foundation of China (Grant No. 51808182) and the National Key Research and Development Project (Grant No. 2019YFD1101002). The authors also appreciate the financial support provided by The Opening Fund of State Key Laboratory of Green Building in Western China (Grant No. LSKF202005). This work was also supported by the China Postdoctoral Science Foundation (Grant No. 2020M670680).

[17] Lue DM, Liu J, Yen T., Experimental study on rectangular CFT columns with high-strength concrete, Journal of Constructional Steel Research, 63(1), 37-44, 2007.

[18] Liew JYR, Xiong M, Xiong D., Design of Concrete Filled Tubular Beam-columns with High Strength Steel and Concrete, Structures, 8, 213-26 2016.

[19] Xiong M, Xiong D, Liew JYR., Axial performance of short concrete filled steel tubes with high- and ultra-high- strength materials, Engineering Structures. 136, 494-510, 2017.

[20] Lyu X, Shu GP, Liew JYR, Du E., Fire Resistance of Steel Tubular Columns Infilled with Ultra-High Strength Concrete. Advanced Steel Construction. 14(3), 438-460, 2018.

[21] Du Y, Chen Z, Yu Y., Behavior of rectangular concrete-filled high-strength steel tubular columns with different aspect ratio, Thin-Walled Structures, 109, 304-318, 2016.

[22] Lee H, Park H, Choi I., Compression loading test for concrete-filled tubular columns with high-strength steel slender section, Journal of Constructional Steel Research, 159, 507-520, 2019.

[23] Ellobody E, Young B., Nonlinear analysis of concrete-filled steel SHS and RHS columns, Thin-Walled Structures, 44(8), 919-930, 2006.

[24] Liu D., Behaviour of eccentrically loaded high-strength rectangular concrete-filled steel tubular columns, Journal of Constructional Steel Research, 62(8), 839-846, 2006.

[25] Choi I, Chung K, Kim C., Experimental study on rectangular CFT columns with different steel grades and thicknesses, Journal of Constructional Steel Research, 130, 109-119, 2017.

[26] Du Y, Chen Z, Richard Liew JY, Xiong M., Rectangular concrete-filled steel tubular beam-columns using high-strength steel: Experiments and design, Journal of Constructional Steel Research, 131, 1-18, 2017.

[27] Du Y, Chen Z, Wang Y, Richard Liew JY., Ultimate resistance behavior of rectangular concrete-filled tubular beam-columns made of high-strength steel, Journal of Constructional Steel Research, 133, 418-433, 2017.

[28] Li G, Chen B, Yang Z, Feng Y., Experimental and numerical behaviour of eccentrically loaded high strength concrete filled high strength square steel tube stub columns, Thin-Walled Structures, 127: 483-499, 2018.

[29] Li G, Yang Z, Lang Y., Experimental Behavior of High Strength Concrete-Filled Square Steel Tube under Bi-Axial Eccentric Loading, Advanced Steel Construction, 6(4), 963-975, 2010.

[30] DB 29-57. Technical Specification for Design of Steel Structure Dwelling Houses, Tianjin Urban Rural Construction Commission, Tianjin, China, 2003.(in Chinese)

[31] Han L, Yao G, Tao Z. Performance of concrete-filled thin-walled steel tubes under pure torsion. Thin-Walled Structures, 45(1): 24-36, 2007

[32] Eurocode 4, EN 1994-1-1 Design of composite steel and concrete structures, Part 1.1 General rules and rules for buildings, British Standards Institution, 2004.

[33] ANSI/AISC 360-16, Specification for Structural Steel Buildings. American Institute of Steel Construction, Chicago, USA, 2010

[34] AIJ. Recommendations for design and construction of concrete filled steel tubular structures. Architectural Institute of Japan , Japan, 2008.

[35] GB50936-2014, Technical code for concrete filled steel tubular structures. Standard Press of China, Beijing, China, 2014.(in Chinese) 